Article

\title{
Interface Characteristics of Ti-Clad V-4Cr-4Ti Alloy Diffusion-Bonded Joint Produced by Hot Forging
}

\author{
Gaowei Zhang ${ }^{(\mathbb{D}}$, Wentuo Han, Xiaoou Yi and Farong Wan * \\ School of Materials Science and Engineering, University of Science and Technology Beijing, Beijing 100083, \\ China; gaoweizh508@163.com (G.Z.); han-wt@ustb.edu.cn (W.H.); xiaoouyi@ustb.edu.cn (X.Y.) \\ * Correspondence: wanfr@mater.ustb.edu.cn; Tel.: +86-010-6233-3724
}

Received: 5 March 2018; Accepted: 3 April 2018; Published: 7 April 2018

\begin{abstract}
Diffusion bonding of $\mathrm{V}-4 \mathrm{Cr}-4 \mathrm{Ti}$ alloy to pure titanium (Ti) was carried out by hot forging in the temperature range between $1150{ }^{\circ} \mathrm{C}$ and $950{ }^{\circ} \mathrm{C}$. The microstructure and mechanical properties of the bonded joint were determined by using light optical microscopy $(\mathrm{OM})$, scanning electron microscopy (SEM), energy dispersive spectroscopy (EDS), micro-hardness measurements, and shear tests. The results indicate that the sound dissimilar joint can be obtained through hot forging processes. The interface has a width of about $100 \mu \mathrm{m}$ and can be divided into two distinctive zones: a Widmanstatten structure zone and a $\beta$-Ti phase structure zone. According to the micro-hardness distribution profile across the substrates and the interface, the largest hardness of $332 \mathrm{HV}$ was measured in a narrow region between the Ti substrate and the joint, which is remarkably higher than that of the substrates (Ti of $190 \mathrm{HV}$ and V-4Cr-4Ti alloy of $258 \mathrm{HV}$ ). The lowest hardness of only $182 \mathrm{HV}$ was found in a region in the V-4Cr-4Ti substrate adjacent to the joint. The shear test showed that the joint has a bonding strength higher than $165 \mathrm{MPa}$ and a fracture of the joint took place in the region with the highest hardness.
\end{abstract}

Keywords: V-4Cr-4Ti/Ti joint; interface characteristics; hot forging; diffusion bonded; interface strength

\section{Introduction}

The development of electrically insulating coatings is extremely important for the lithium/ vanadium $(\mathrm{Li} / \mathrm{V})$ blanket of the fusion reactor $[1,2]$. The coatings have to possess sufficiently high resistance and stability in liquid $\mathrm{Li}$ in order to mitigate the magnethydrodynamic (MHD) pressure drop to an acceptable level [3]. However, only a few materials constitute possible solutions, according to previous research work [3-6], because the liquid lithium acting as a strong reducing agent can dissolve most materials, especially at elevated temperatures [6].

A number of studies have shown that aluminum nitride (AIN) is a promising candidate that has high electrical resistivity and good compatibility with liquid $\mathrm{Li}$ as well as excellent resistance to irradiation [7-9]. In addition, AlN coatings can be potentially realized by in situ formation in liquid $\mathrm{Li}$ [10], which favor coating fabrication on surfaces with complex geometries. For monolayer AlN coatings, through-thickness defects are easy to develop since their thickness is usually limited to only a few tens of microns [11]. The presence of the through-thickness defects may degrade the integrity and insulation properties of the coating [11,12]. The reason for this is that the V-alloy substrate absorbs nitrogen from liquid $\mathrm{Li}$ to form vanadium nitride (VN), which breaks the dissolution equilibrium [11]. To solve this stability issue, the development of multilayer coatings is thought to be an effective approach [13-15] and the "V-alloy/AlN/metal" (e.g., metal = Cr, $\mathrm{Nb}$ [13]) multilayer coating has been investigated. This bilayer coating with an integrated top metal layer can provide enough resistance. However, the integrity and corrosion issue of the metal layer in Li could be problematic because of the 
chemical interactions between the metal layer and the impurities (e.g., $\mathrm{N}, \mathrm{C}$ ) in lithium [16,17]. In order to overcome the weakness, the "V-alloy/Ti/ AlN" bilayer coating is proposed by the authors for the first time. This coating with a Ti interlayer is aimed at enhancing the stability of AlN coating in $\mathrm{Li}$ and depends on the formation of a titanium nitride (TiN) reaction layer at the Ti/ AlN interface using an appropriate thermal treatment [18-20]. The TiN layer, which is chemically stable in lithium [4,6], is expected to function as a protective layer to prevent the further invasion of lithium into the V-alloy substrate despite the possible production of any through-thickness defects in the top AlN layer.

The Ti interlayer plays an important role in combing the V-alloy and AlN coating, which is why it is of great scientific and practical value to study the interface characteristics of V-alloy/Ti interface and $\mathrm{Ti} / \mathrm{AlN}$ interface for fabricating the target $\mathrm{V}$-alloy/Ti/AlN coating. However, the research on the interface characteristics of $\mathrm{V}$-alloy/Ti joint has not been reported so far. In this work, the $\mathrm{V}-4 \mathrm{Cr}-4 \mathrm{Ti} / \mathrm{Ti}$ diffusion bonded joint was produced by hot forging and the microstructure and mechanical properties of the joint were characterized.

\section{Materials and Methods}

The vanadium alloy reacts readily with oxygen at elevated temperatures even in a low gas pressure environment [21]. Owing to this behavior, the alloy is usually covered with an alloy jacket (e.g., steel) to avoid oxidation during the hot processing [22]. Since we wished to study the diffusion bonding of the $\mathrm{V}-4 \mathrm{Cr}-4 \mathrm{Ti}$ alloy to commercially pure Ti metal, a $\mathrm{V}-4 \mathrm{Cr}-4 \mathrm{Ti}$ alloy rod and a Ti metal pipe as the covering jacket were employed for the bonding (see Figure 1a). The chemical compositions of the V-4Cr-4Ti alloy and the pure Ti are listed in Table 1 . The $\mathrm{V}-4 \mathrm{Cr}-4 \mathrm{Ti}$ alloy rod was machined to a final size of $28 \mathrm{~mm}$ (diameter) $\times 75 \mathrm{~mm}$ (length) and then underwent turning and fine grinding. The Ti pipe was machined to be the jacket with a size of $28.2 \mathrm{~mm}$ (internal diameter) $\times 75 \mathrm{~mm}$ (length) $\times 8 \mathrm{~mm}$ (thickness). The V-alloy rod and Ti pipe were ultrasonically cleaned in acetone and dried prior to assembly. The two ends of the pipe were joined with pure Ti plates $(44 \mathrm{~mm}$ in diameter $\times 10 \mathrm{~mm}$ in thickness) by electron beam welding in a vacuum. The welded specimen adopted a cylindrical geometry after hot forging and lathe turning for later bonding (see Figure 1b).

(a)

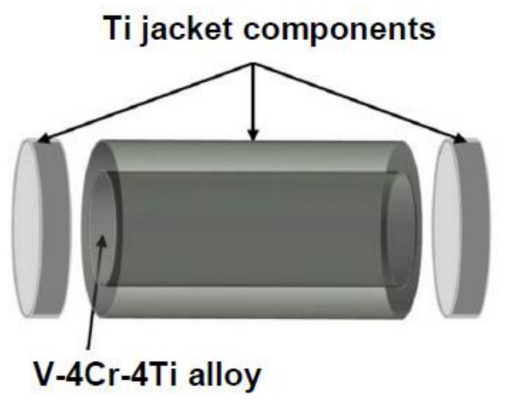

(c)

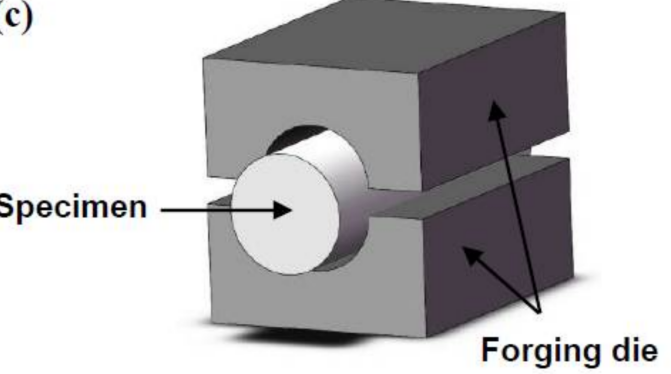

(b)

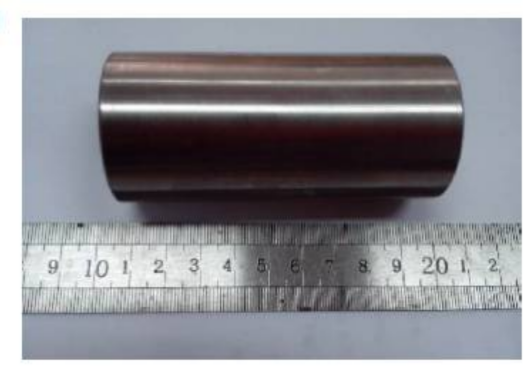

(d)

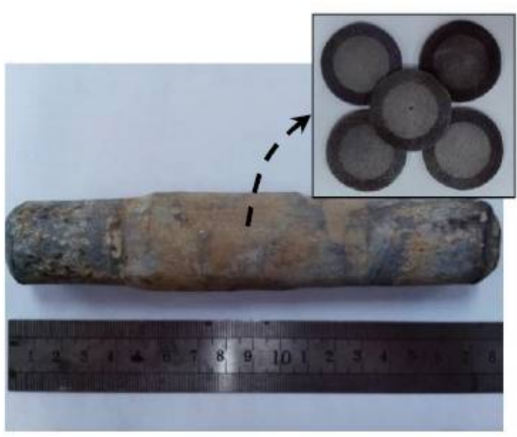

Figure 1. Schematic diagrams illustrating the specimen preparation and hot forging process: (a) the assembly of materials; (b) the assembled piece prior to forging; (c) the geometry of hot forging; (d) the assembled piece after forging. 
The specimen was heat treated in a furnace at $1150{ }^{\circ} \mathrm{C}$ for $2 \mathrm{~h}$ before the hot forging. The geometry of the forging die is illustrated in Figure 1c. The internal diameter of the die is a little smaller than the specimen in order to bond the Ti jacket to the $\mathrm{V}$-alloy through a radial deformation process. Several dies with different diameters $(\Phi=42 \mathrm{~mm}, 39 \mathrm{~mm}, 36 \mathrm{~mm}, 33 \mathrm{~mm}$, and $29 \mathrm{~mm}$ ) were sequentially used. The forging temperature measured by a handled digital thermometer was always kept in the range between $1150{ }^{\circ} \mathrm{C}$ and $950{ }^{\circ} \mathrm{C}$. The specimen was reheated in the furnace when cooled down to about $950{ }^{\circ} \mathrm{C}$ during the forging. Lastly, it was forged to $29 \mathrm{~mm}$ in diameter and then air cooled to room temperature. Cross-sections of the specimen (see Figure 1d) were sliced and mirror polished, which ensured that the specimen was ready for observation by conventional technique. The interface was etched for $10 \mathrm{~s}$ in an acetic solution $(30 \mathrm{~mL})$ of $\mathrm{HNO}(10 \mathrm{~mL})$ and $\mathrm{HF}(10 \mathrm{~mL})$ followed by optical microscope observation (OLYMPUS BX51M, Tokyo, Japan) to reveal the structural evolution. The joint was also examined with a scanning electron microscope (SEM, Zeiss Auriga, Germany) to observe the finer structure and determine the chemical composition distribution across the joint and the fracture surface by using energy dispersive X-ray spectroscopy (EDS, Oxford Instruments, Oxford, UK). A Vickers hardness tester (WOLPERT 430SVD, Norwood, MA, USA) with a $10 \mathrm{~g}$ load for $30 \mathrm{~s}$ was used to investigate the micro-hardness distribution across the joint.

Table 1. Chemical composition of the parent materials (wt \%).

\begin{tabular}{cccccccc}
\hline Material & $\mathbf{V}$ & $\mathbf{T i}$ & $\mathbf{C r}$ & $\mathbf{F e}$ & $\mathbf{C}$ & $\mathbf{N}$ & $\mathbf{O}$ \\
\hline V-4Cr-4Ti & Bal. & 3.36 & 3.45 & - & 0.052 & 0.001 & 0.033 \\
Pure Ti & - & Bal. & - & 0.2 & 0.1 & 0.05 & 0.2 \\
\hline
\end{tabular}

\section{Results and Discussion}

Figure 2 shows the optical micrograph of the typical V-4Cr-4Ti/Ti bonded interface. It presents a smooth interface without any observable cracks. The range of the diffusion interface is approximately $100 \mu \mathrm{m}$ wide and can be divided into two distinct zones. Zone I lies close to the Ti side and is about $70 \mu \mathrm{m}$ in width. It features a needle-cluster structure. At the same time, zone II is about $30 \mu \mathrm{m}$ wide and is located close to the V-alloy side, which features a uniform band structure. This interface microstructure resembles the pure Ti/steel diffusion-bonded joint [23-25], which is mainly attributed to the varied concentration of $\beta$-Ti stabilizers (e.g., Fe, V, or $\mathrm{Cr}$ ) across the interface [26,27]. According to [23-27], zone II should be the uniform $\beta$-Ti phase band structure because of the high concentration of $\mathrm{V}$ (see Figure 3). Zone II is adjacent to the V-alloy substrate and is rich in V content, which favors $\beta$-Ti solid solution phase stability up to room temperature [27]. Since the $\beta$-Ti phase is difficult to etch [23], zone II appears clean without visible metallurgical structure [25]. When the concentration of the stabilizers is relatively low, it may lead to partial $\beta \rightarrow \alpha$ phase transformation and form the Widmanstätten structure [26]. Zone I is located far from the V-alloy substrate and its characteristic Widmanstätten structure $(\alpha+\beta$ phases) should be attributed to the lower concentration of $\mathrm{V}$ and $\mathrm{Cr}$ ( $\beta$-Ti stabilizers).

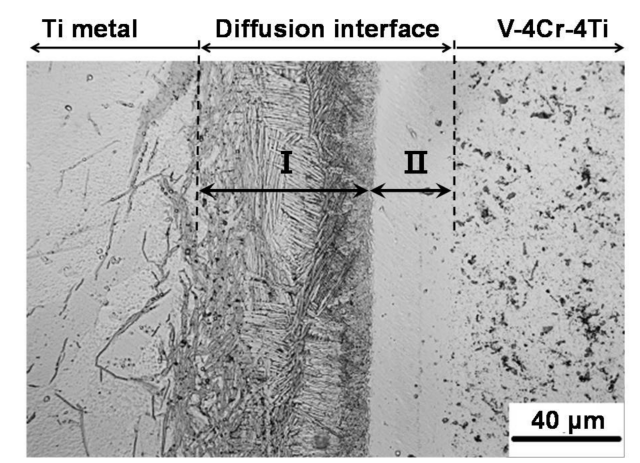

Figure 2. Optical micrograph of a typical V-4Cr-4Ti/Ti bonded interface. 
The diffusional behavior of $\mathrm{V}, \mathrm{Cr}$, and Ti across the joint was determined by EDS, which is shown in Figure 3. It is shown that the concentration of these elements change gradually across zone I while drastic changes are observed in zone II, which should act as a boundary of the interface. The EDS analysis shows that the $\mathrm{V}$ concentration in zone $\mathrm{I}$ is lower than $\sim 16 \mathrm{wt} \%$ while it ranges from $\sim 17$ to $93 \mathrm{wt} \%$ in zone II. The $\mathrm{Cr}$ concentration across the interface is very low even in zone II. Since the diffusion coefficient for $\mathrm{Cr}\left(\mathrm{D}_{\mathrm{Cr}}\right)$ in $\mathrm{V}$ is so small (e.g., $\mathrm{D}_{\mathrm{Cr}}=5.84 \times 10^{-17} \mathrm{~m}^{2} / \mathrm{s}$ at $1383 \mathrm{~K}$ [28]), the diffusion distance of $\mathrm{Cr}$ should be limited in the $\mathrm{V}-4 \mathrm{Cr}-4 \mathrm{Ti}$ alloy.

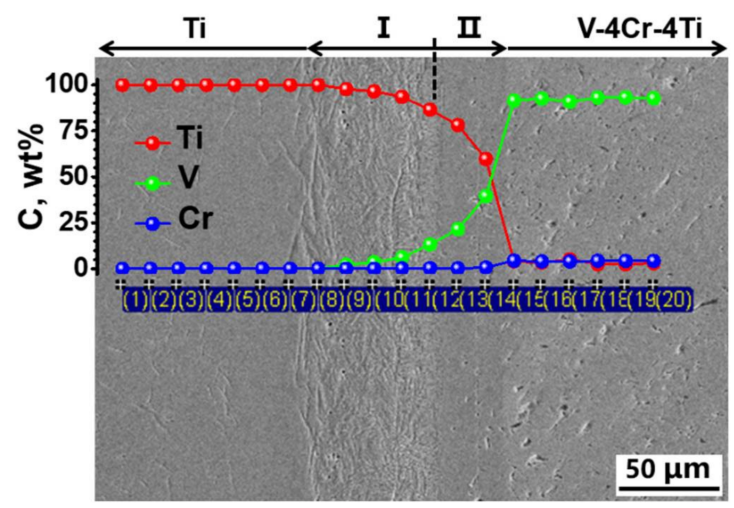

Figure 3. Concentration profiles of $\mathrm{Ti}, \mathrm{V}$, and $\mathrm{Cr}$ across the chemically etched $\mathrm{V}-4 \mathrm{Cr}-4 \mathrm{Ti} / \mathrm{Ti}$ joint.

The mutual diffusion of the elements in the parent alloys promotes the formation of the $\mathrm{V}-4 \mathrm{Cr}-4 \mathrm{Ti} / \mathrm{Ti}$ joint, which changed the microstructure and also the hardness. Vickers hardness measurements were performed across the substrates and the joint. According to the hardness distribution profile, six characteristic parts (A, B, C, D, E, and F) were defined (see Figure 4). Part $\mathrm{A}$ and $\mathrm{F}$ refer to the regions in $\mathrm{Ti}$ and $\mathrm{V}-4 \mathrm{Cr}-4 \mathrm{Ti}$ alloy substrates far from the bonded interface, which measures $190 \mathrm{HV}$ and $258 \mathrm{HV}$, respectively. Part C corresponds to zone I and part D to zone II. Part B and E are the intermediate layers shown in Figure 4. It can be found that the highest hardness (332 HV) appeared at the boundary of part $\mathrm{C}$ adjacent to the Ti substrate because of the stress concentration induced by the Ti phase transformation during the cooling after the forging process. It has been shown that the appropriate post weld heat treatment (PWHT) can be effective for decreasing the hardness and increasing the toughness of some welded joints [29,30]. Therefore, the PWHT could also be adopted to recover the hardness of the V-4Cr-4Ti/Ti joint. Part E lays in the V-alloy substrate adjacent to the joint and exhibits the lowest hardness at only $180 \mathrm{HV}$. Nishimura et al. [31] reported that the typical precipitates such as Ti-CON in the $\mathrm{V}-4 \mathrm{Cr}-4 \mathrm{Ti}$ alloy could be decomposed at the forging temperature. Therefore, it is expected that the solid-solution hardening agents, $\mathrm{C}, \mathrm{O}$, and N, might be transferred from the $\mathrm{V}-4 \mathrm{Cr}-4 \mathrm{Ti}$ alloy to the Ti substrate during the forging process due to their chemical affinity. During the cooling after forging, the Ti-CON substance should be re-produced. However, its amount in part $\mathrm{E}$ should be less than the original one because of the loss of the interstitial impurities. Therefore, the region with less precipitate exhibits less hardness than the V-alloy substrate. In addition, the average hardness of Ti and V-alloy substrates were $190 \mathrm{HV}$ and $258 \mathrm{HV}$, respectively.

The bonding strength of the $\mathrm{V}-4 \mathrm{Cr}-4 \mathrm{Ti} / \mathrm{Ti}$ joint was studied using the push-out method [32] and the schematic diagram is shown in Figure $5 \mathrm{a}$. The bonding strength $(\tau)$ of the joint can be approximately calculated using the formula below.

$$
\tau=\frac{F}{\pi D h^{\prime}}
$$

where $F$ is the applied maximum load, $D$ is the diameter of the central V-4Cr-4Ti rod, and $h$ is the disc thickness. 


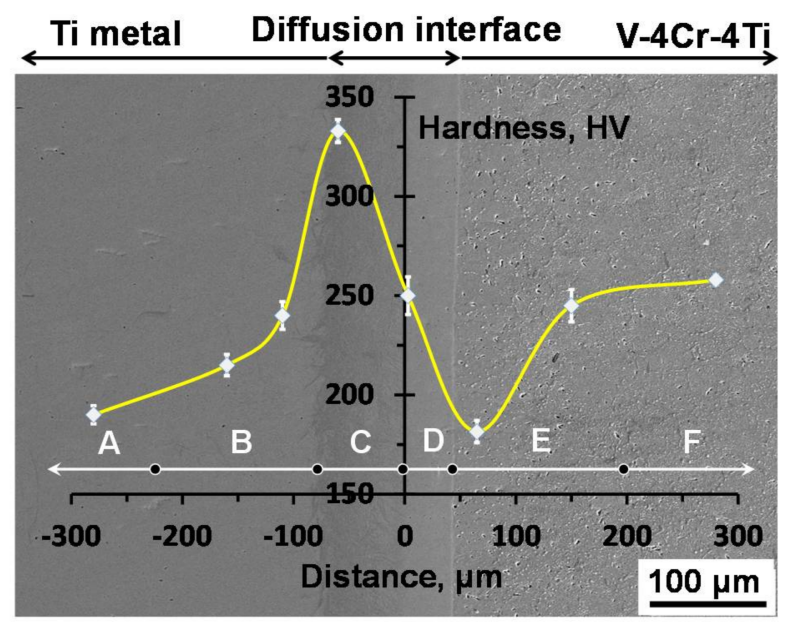

Figure 4. Vickers-hardness distribution across the $\mathrm{V}-4 \mathrm{Cr}-4 \mathrm{Ti} / \mathrm{Ti}$ joint.

Two types of failure of the joint were observed during the shear tests: type one occurred around the joint (e.g., specimen $1 \#$ in Figure $5 \mathrm{~b}$ ) and type two occurred in the central $\mathrm{V}-4 \mathrm{Cr}-4 \mathrm{Ti}$ alloy (e.g., specimen 2\# in Figure 5b). For the first type, the failure appears at a narrow region between the Ti substrate and the joint, which was confirmed by SEM (see Figure 6). This is probably ascribed to the stress concentration produced by phase transformation of Ti during the cooling process. When Ti metal is cooled from a high forging temperature $\left(950{ }^{\circ} \mathrm{C}\right.$ or higher) to room temperature, it transforms from the bcc structure ( $\beta$-Ti) to the hcp structure $(\alpha-\mathrm{Ti})$ [33]. The dilational stress produced at the interface results in the extreme hardness. In addition, since the push-out test is terminated once the specimen has partly failed during the test, the bonding strength of the joint should be higher than the calculated value of $165 \mathrm{MPa}$ (see Figure 5b).

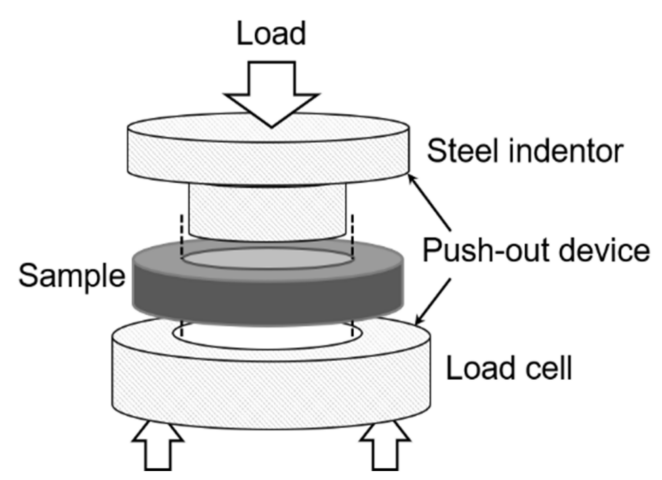

(a)

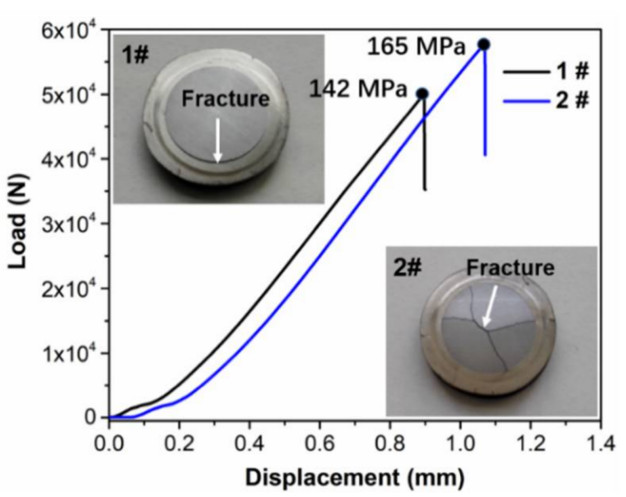

(b)

Figure 5. Bonding strength tests: (a) schematic diagram of the apparatus; (b) load-displacement curves of the $\mathrm{V}-4 \mathrm{Cr}-4 \mathrm{Ti} / \mathrm{Ti}$ joint.

The fracture surface on the side of the $\mathrm{V}-4 \mathrm{Cr}-4 \mathrm{Ti}$ alloy was analyzed by using SEM and EDS. A relatively smooth fracture surface morphology was observed at low magnification, which is shown in Figure 6a-1,b-1. At higher magnification, the fracture surface had a plastic deformation during the shear punch test according to the surface microstructure, which is shown in Figure 6a-2,b-2. EDS analysis revealed that the Ti concentration of the typical fracture surfaces on the $\mathrm{V}-4 \mathrm{Cr}-4 \mathrm{Ti}$ alloy side was nearly $100 \%$ (see Figure $6 a-3, b-3$ ), which indicates the failure of the joint took place in a narrow region in the joint close to the Ti substrate. It was observed that the phase transformation of the Ti substrate gave rise to the extreme hardness as well as the weakness in the transitional region. 
(a-1)
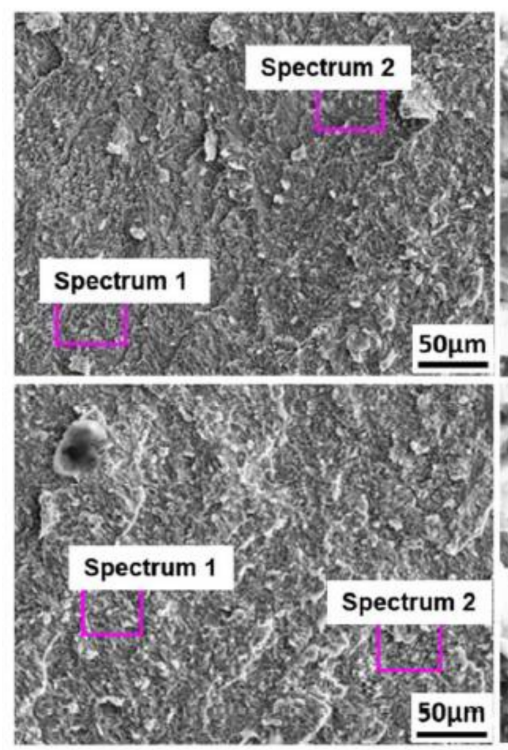

(b-1) (a-2)

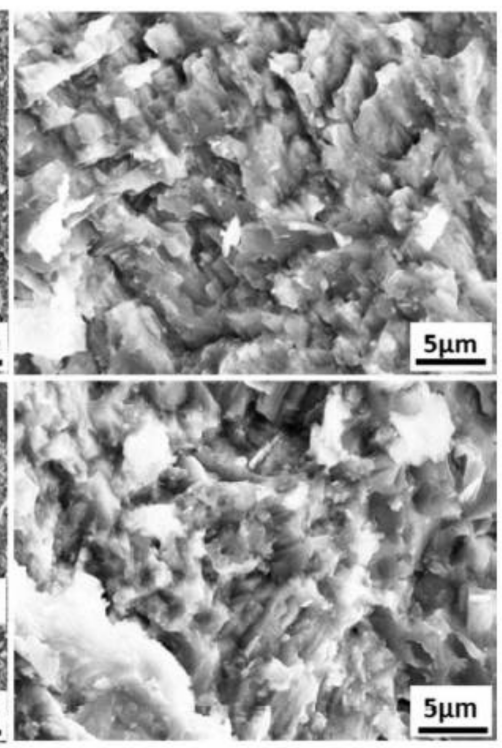

(b-2) (a-3)
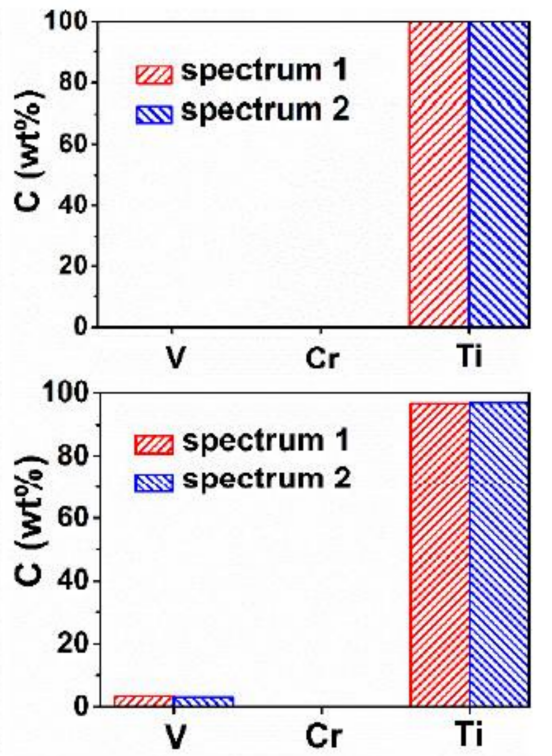

(b-3)

Figure 6. Scanning electron microscope (SEM) micrographs and chemical analysis of the fracture surface on the V-4Cr-4Ti alloy side: (a-1,b-1) surface appearance at $1000 \times$ magnification; (a-2,b-2) surface appearance at 10,000 $\times$ magnification; (a-3,b-3) chemical analysis of the selected areas in (a-1,b-1), respectively.

\section{Conclusions}

A dissimilar joint of the $\mathrm{V}-4 \mathrm{Cr}-4 \mathrm{Ti}$ alloy/pure Ti was successfully prepared by using the hot forging technique in the temperature range between $1150{ }^{\circ} \mathrm{C}$ and $950{ }^{\circ} \mathrm{C}$. The microstructure and mechanical properties of the joint were studied. Based on the results, conclusions are shown below.

(1) A sound diffusion-bonded interface was obtained. The interface was about $100 \mu \mathrm{m}$ in width and can be divided into two different zones in which zone I is the Widmanstatten structure consisting of an $\alpha$-Ti phase and $\beta$-Ti phase and zone II-adjacent to $\mathrm{V}-4 \mathrm{Cr}-4 \mathrm{Ti}$ substrate-is the single $\beta$-Ti phase band structure.

(2) A maximum micro-hardness value of $332 \mathrm{HV}$ was measured at the transitional region between the Ti substrate and the $\mathrm{V}-4 \mathrm{Cr}-4 \mathrm{Ti} / \mathrm{Ti}$ joint while the minimum level of hardness reaching only $182 \mathrm{HV}$ was located in a region in the $\mathrm{V}-4 \mathrm{Cr}-4 \mathrm{Ti}$ substrate adjacent to the joint. The average hardness of the Ti substrate and the V-4Cr-4Ti alloy are $190 \mathrm{HV}$ and $258 \mathrm{HV}$, respectively.

(3) The bonding strength of the $\mathrm{V}-4 \mathrm{Cr}-4 \mathrm{Ti} / \mathrm{Ti}$ joint was higher than $165 \mathrm{MPa}$, according to the results of push-out tests. It was demonstrated that the fracture of the joint took place in the region with the highest hardness, which is probably ascribed to the stress concentration caused by the phase transformation of the Ti substrate during the air cooling process.

Acknowledgments: This research is supported by the National Magnetic Confinement Fusion Science Program of China (No. 2014GB120000), the Beijing Natural Science Foundation (No. 2182043), and the Fundamental Research Funds for the Central Universities (No. FRF-TP-16-029A1).

Author Contributions: Farong Wan conceived and designed the experiments. Gaowei Zhang performed the experiments and contributed with reagents/materials/analysis tools. Gaowei Zhang, Farong Wan, Wentuo Han, and Xiaoou Yi analyzed the data. Gaowei Zhang wrote the paper.

Conflicts of Interest: The authors declare no conflict of interest. 


\section{References}

1. Malang, S.; Leroy, P.; Casini, G.P.; Mattas, R.F. Crucial issues on liquid metal blanket design. Fusion Eng. Des. 1991, 16, 95-109. [CrossRef]

2. Barleon, L.; Casal, V.; Lenhart, L. MHD flow in liquid-metal-cooled blankets. Fusion Eng. Des. 1991, 14, 401-412. [CrossRef]

3. Malang, S.; Borgstedt, H.U.; Farnum, E.H.; Natesan, K.; Vitkovski, I.V. Development of insulating coatings for liquid metal blankets. Fusion Eng. Des. 1995, 27, 570-586. [CrossRef]

4. Muroga, T.; Pint, B.A. Progress in the development of insulator coating for liquid lithium blankets. Fusion Eng. Des. 2010, 85, 1301-1306. [CrossRef]

5. Pint, B.A.; Devan, J.H.; Distefano, J.R. Temperature limits on the compatibility of insulating ceramics in lithium. J. Nucl. Mater. 2002, 307-311, 1344-1350. [CrossRef]

6. Hubberstey, P.; Sample, T. Thermodynamics of the interactions between liquid breeders and ceramic coating materials. J. Nucl. Mater. 1997, 248, 140-146. [CrossRef]

7. Natesan, K.; Reed, C.B.; Rink, D.L.; Haglund, R.C. Development and performance of aluminum nitride insulating coatings for application in a lithium environment. J. Nucl. Mater. 1998, 258-263, 488-494. [CrossRef]

8. Suzuki, A.; Muroga, T.; Pint, B.A.; Yoneoka, T.; Tanaka, S. Corrosion behaviour of AlN for self-cooled Li/V blanket application. Fusion Eng. Des. 2003, 69, 397-401. [CrossRef]

9. Smith, D.L.; Konys, J.; Muroga, T.; Evitkhin, V. Development of coatings for fusion power applications. J. Nucl. Mater. 2002, 307-311, 1314-1322. [CrossRef]

10. Vertkov, A.V.; Evtikhin, V.A.; Lyublinski, I.E. Self-healing electrical insulating coating processes for vanadium alloy-lithium systems. Fusion Eng. Des. 2001, 58-59, 731-735. [CrossRef]

11. Pint, B.A.; Tortorelli, P.F.; Jankowski, A.; Hayes, J.; Muroga, T.; Suzuki, A.; Yeliseyeva, O.I.; Chernov, V.M. Recent progress in the development of electrically insulating coatings for a liquid lithium blanket. J. Nucl. Mater. 2004, 329-333, 119-124. [CrossRef]

12. Terai, T.; Suzuki, A.; Yoneoka, T.; Mitsuyama, T. Compatibility of AlN with liquid lithium. J. Nucl. Mater. 2000, 283-287, 1322-1325. [CrossRef]

13. Vitkovsky, I.V.; Gorunov, A.V.; Engelko, V.I.; Kirillov, I.R. Development and testing of electroinsulating barriers for lithium-vanadium fusion blanket. Fusion Eng. Des. 2002, 61-62, 739-743. [CrossRef]

14. Pint, B.A.; Moser, J.L.; Jankowski, A.; Hayes, J. Compatibility of multi-layer, electrically insulating coatings for vanadium-lithium blankets. J. Nucl. Mater. 2007, 367-370, 1165-1169. [CrossRef]

15. Pint, B.A.; Pawel, S.J.; Howell, M.; Moser, J.L.; Garner, G.W.; Santella, M.L.; TortorelliF, P.F.; Wiffen, W.; DiStefano, J.R. Initial characterization of $\mathrm{V}-4 \mathrm{Cr}-4 \mathrm{Ti}$ and MHD coatings exposed to flowing Li. J. Nucl. Mater. 2009, 386-388, 712-715. [CrossRef]

16. Chopra, O.K.; Smith, D.L. Corrosion behavior of vanadium alloys in flowing lithium. J. Nucl. Mater. 1988, 155-157, 683-689. [CrossRef]

17. Evtikhin, V.A.; Lyublinski, I.E.; Pankratov, V.Y. Vanadium alloys as structural materials for liquid lithium blanket of fusion reactors. J. Nucl. Mater. 1992, 191-194, 924-927. [CrossRef]

18. Yasumoto, T.; Yamakawa, K.; Iwase, N.; Shinosawa, N. Reaction between AlN and Metal Thin Films during High Temperature Annealing. J. Cerem. Soc. Jpn. 1993, 101, 969-973. [CrossRef]

19. He, X.; Yang, S.; Du, Y.; Tao, K. Reaction layer formation at the interface Ti or Zr and AlN. Phys. Stat. Sol. A 1996, 157, 99-106. [CrossRef]

20. He, X.; Yang, S.; Tao, K.; Fan, G. Investigation of the interface reactions of Ti thin films with AlN substrate. J. Mater. Res. 1997, 12, 846-851. [CrossRef]

21. DiStefano, J.R.; DeVan, J.H. Reactions of oxygen with V-Cr-Ti alloys. J. Nucl. Mater. 1997, 249, $150-158$. [CrossRef]

22. Potapenko, M.M.; Drobishev, V.A.; Filkin, V.Y.; Gubkin, I. Manufacture of semifinished items of alloys $\mathrm{V}-4 \mathrm{Ti}-4 \mathrm{Cr}$ and V-10Ti-5Cr for use as a structural material in fusion application. J. Nucl. Mater. 1996, 233-237, 438-441. [CrossRef]

23. Bhanumurthy, K.; Kale, G.B. Reactive diffusion between titanium and stainless steel. J. Mater. Sci. Lett. 1993, 12, 1879-1881. [CrossRef] 
24. Kundu, S.; Ghosh, M.; Laik, A.; Bhanumurthy, K.; Kale, G.B.; Chatterjee, S. Diffusion bonding of commercially pure titanium to 304 stainless steel using copper interlayer. Mater. Sci. Eng. A 2005, 407, 154-160. [CrossRef]

25. Qin, B.; Sheng, G.M.; Huang, J.W.; Zhou, B.; Qiu, S.Y.; Li, C. Phase transformation diffusion bonding of titanium alloy with stainless steel. Mater. Charact. 2006, 56, 32-38. [CrossRef]

26. Sridhar, G.; Kutumbarao, V.V.; Sarma, D.S. The influence of heat treatment on the structure and properties of a near- $\alpha$ titanium alloy. Metall. Trans. A 1987, 18A, 877-891. [CrossRef]

27. Gil, F.J.; Ginebra, M.P.; Manero, J.M.; Planell, J.A. Formation of $\alpha$-Widmanstätten structure: Effects of grain size and cooling rate on the Widmanstätten morphologies and on the mechanical properties in Ti6Al4V alloy. J. Alloys Compd. 2001, 329, 142-152. [CrossRef]

28. Pelleg, J. Diffusion of ${ }^{51} \mathrm{Cr}$ in vanadium. Philos. Mag. A 1995, 71, 431-439. [CrossRef]

29. Tsisar, V.; Nagasaka, T.; Flem, M.L.; Yeliseyeva, O.; Konys, J.; Muroga, T. Effect of post-weld heat treatment on microstructure, hardness and low-temperature impact toughness of electron beam welds of NIFS-HEAT-2 and CEA-J57 heats of V-4Ti-4Cr alloy. Nucl. Mater. Energy 2016, 9, 436-440. [CrossRef]

30. Chennaiah, M.B.; Kumar, P.N.; Rao, K.P. Effect of PWHT on the hardness and fractured microstructure of IS-103Cr1 welded joint. Mater. Today Proc. 2017, 4, 1193-1198. [CrossRef]

31. Nishimura, A.; Iwahori, A.; Heo, N.J.; Nagasaka, T.; Muroga, T.; Tanaka, S.I. Effect of precipitation and solution behavior of impurities on mechanical properties of low activation vanadium alloy. J. Nucl. Mater. 2004, 329, 438-441. [CrossRef]

32. Dezellus, O.; Milani, L.; Bosselet, F.; Sacerdote-Peronnet, M.; Rouby, D.; Viala, J.-C. Mechanical testing of titanium/aluminium-silicon interfaces by push-out. J. Mater. Sci. 2008, 43, 1749-1756. [CrossRef]

33. Seward, G.G.E.; Celotto, S.; Prior, D.J.; Wheeler, J.; Pond, R.C. In situ SEM-EBSD observations of the hcp to bcc phase transformation in commercially pure titanium. Acta Mater. 2004, 52, 821-832. [CrossRef]

(C) 2018 by the authors. Licensee MDPI, Basel, Switzerland. This article is an open access article distributed under the terms and conditions of the Creative Commons Attribution (CC BY) license (http:/ / creativecommons.org/licenses/by/4.0/). 